(c) American Dairy Science Association, 2005.

\title{
Derivation of Sustainable Breeding Goals for Dairy Cattle Using Selection Index Theory
}

\author{
H. M. Nielsen, ${ }^{1, \star}$ L. G. Christensen, ${ }^{2}$ and A. F. Groen ${ }^{3}$ \\ ${ }^{1}$ Department of Animal Breeding and Genetics, Danish Institute of Agricultural Sciences, \\ Research Centre Foulum, PO Box 50, DK-8830 Tjele, Denmark \\ ${ }^{2}$ Department of Large Animal Sciences, The Royal Veterinary and Agricultural University, \\ Grønnegårdsvej 8, DK-1870 Frederiksberg C, Denmark \\ ${ }^{3}$ Wageningen Institute of Animal Sciences, Wageningen University, PO Box 338, \\ Wageningen, the Netherlands
}

\begin{abstract}
The objective was to present 2 methods for the derivation of nonmarket values for functional traits in dairy cattle using deterministic simulation and selection index theory. A nonmarket value can be a value representing animal welfare and societal influences for animal production, which can be added to market economic values in the breeding goal to define sustainable breeding goals. The first method was restricted indices. A consequence of adding a nonmarket value to a market economic value for a given functional trait is less selection emphasis on milk yield. In the second method, the loss in selection response in milk resulting from greater emphasis on functional traits was quantified. The 2 methods were demonstrated using a breeding goal for dairy cattle with 4 traits (milk yield, mastitis resistance, conception rate, and stillbirth). Nonmarket values derived separately using restricted indices were 0.4 and 2.6 times the value of market economic values for mastitis resistance and conception rate, respectively. Nonmarket values for mastitis resistance and conception rate were both lower when derived simultaneously than when derived separately. This was due to the positive genetic correlation between mastitis resistance and conception rate, and because both traits are negatively correlated with milk yield. Using the second method and accepting a 5\% loss in selection response for milk yield, nonmarket values for mastitis, conception rate, and stillbirth were $0.3,1.4$, and 2.9 times the market economic values. It was concluded that the 2 methods could be used to derive nonmarket values for functional traits in dairy cattle.
\end{abstract}

\footnotetext{
Received September 3, 2004.

Accepted December 20, 2004.

Corresponding author: H. M. Nielsen; e-mail: hanne.marie. nielsen@umb.no.

*Current address: Department of Animal and Aquacultural Sciences, Norwegian University of Life Sciences, PO Box 5003, 1432 Ås, Norway.
}

(Key words: dairy cattle, breeding objective, restricted index, sustainability)

Abbreviation key: $\mathbf{C O N C R}=$ conception rate, $\mathbf{E V}=$ market economic values, MAST $=$ mastitis resistance, $\mathbf{M Y}=$ milk yield, $\mathbf{N V}=$ nonmarket values, $\mathbf{S R}=$ selection response, $\mathbf{S T B}=$ stillbirth .

\section{INTRODUCTION}

Breeding for dairy cattle worldwide has primarily focused on improving production traits. Selection for production traits only will lead to deterioration of functional traits (see review by Rauw et al., 1998), which is in conflict with animal welfare (Sandøe et al., 1999). Currently, however, the trend in dairy cattle is towards total merit indices and balanced breeding goals with explicit emphasis on functional traits (Mark, 2004). Even with a balanced breeding goal with emphasis on functional traits, deterioration of functional traits is not necessarily avoided (Christensen, 1998b).

Traditionally, economic values in the breeding goal are derived using profit equations (Brascamp et al., 1985; Dekkers and Gibson, 1998). When deriving economic values, the primary goal is to maximize farmer profit of the dairy cattle production system, which is based solely on the market economy (e.g., Groen, 1989). Due to increased public concern about animal health and welfare, it is also relevant to include social and ethical aspects of animal production when defining the breeding goal (Groen et al., 1997; Olesen et al., 2000). Sustainable livestock production can be defined as ecological production, which takes environment and biodiversity into account and is ethically and economically sustainable (Torp Donner and Juga, 1997). A sustainable breeding goal can be defined by weighing each trait in the breeding goal by a so-called nonmarket value (NV) and by traditionally derived economic values (market economic values, EV) (Olesen et al., 2000). The $\mathrm{NV}$ is a value to account for improved animal welfare and social aspects in the definition of the breeding goal. 
Table 1. Genetic, phenotypic, and economic parameters for milk yield, mastitis resistance, conception rate, and stillbirth. Heritabilities (diagonal), genetic correlations (above diagonal), and phenotypic correlations (below diagonal).

\begin{tabular}{|c|c|c|c|c|c|c|}
\hline Trait $^{1}$ & $\begin{array}{l}\text { Milk } \\
\text { yield }\end{array}$ & $\begin{array}{l}\text { Mastitis } \\
\text { resistance }\end{array}$ & $\begin{array}{l}\text { Conception } \\
\text { rate }\end{array}$ & Stillbirth & $\sigma_{\mathrm{P}}^{2}$ & $\begin{array}{l}\text { Market } \\
\text { economic } \\
\text { value }\end{array}$ \\
\hline Milk yield & 0.28 & -0.35 & -0.35 & 0 & 530 & 0.28 \\
\hline Mastitis resistance & 0.03 & 0.04 & 0.20 & 0 & 1 & 163 \\
\hline Conception rate & -0.10 & 0 & 0.03 & 0 & 33 & 1.98 \\
\hline Stillbirth & 0 & 0 & 0 & 0.04 & 24 & -1.63 \\
\hline
\end{tabular}

${ }^{1}$ Units: milk $=\mathrm{kg} / \mathrm{cow}$ per $\mathrm{yr}$; mastitis $=$ incidence/cow per yr; conception rate and stillbirth $=\% /$ cow per yr; market economic value $=€ /$ unit per cow per yr.

${ }^{2}$ Phenotypic standard deviation.

Derivations of NV are complicated because these must be derived at the sector level with detailed modeling of the whole dairy cattle sector from producer to consumer. Alternatively, the sector level can be mimicked by evaluating the effect of including NV by sensitivity analysis using index calculations (Olesen et al., 2000). Even though tools for deriving NV have been proposed (Olesen et al., 1999), publications showing how to assign NV to dairy cattle traits are scarce.

The main objective of this study was to present 2 methods to derive NV using deterministic simulation and selection index theory. Initially, we applied principles by Olesen et al. (2000) to illustrate the effect on selection response of including $\mathrm{NV}$ in a breeding goal for dairy cattle containing milk yield, mastitis resistance, conception rate, and stillbirth. Desired gain indices can possibly be used to derive NV (Olesen et al., 1999). We tested this premise by deriving NV using restricted indices. A consequence of adding an $\mathrm{NV}$ to an $\mathrm{EV}$ for a given functional trait is less selection emphasis on milk yield. The second method was therefore based on the loss in selection response in milk by improving functional traits.

\section{MATERIALS AND METHODS}

\section{Breeding Structure, Traits, Genetic, and Economic Parameters}

For reasons of simplicity and because selection of dairy sires determines the largest amount of genetic gain, we only considered the selection paths of progenytested sires to breed cows and sires, respectively. The progeny group per sire was assumed to be 100 daughters, and $5 \%$ of tested bulls were selected. The following 4 traits were included; milk yield (MY), mastitis resistance (MAST), conception rate (CONCR), and stillbirth (STB). Assumed heritabilities and genetic and phenotypic correlations (Table 1) were based on the review by Sørensen (1999). Market economic values were those reported by Nielsen (2004) representing the current Danish situation for dairy cattle.

\section{Prediction of Selection Response}

In this study, selection response (SR) was defined as genetic superiority of the selected bulls after one round of selection. Selection response for each trait was:

$$
\mathrm{SR}_{\mathrm{T}}=\frac{\sigma_{\mathrm{IT}}}{\sigma_{\mathrm{I}}} \times \mathrm{i}
$$

where $\mathrm{s}_{\mathrm{IT}}$ is the covariance between index and trait $\mathrm{T}$, $\mathrm{i}$ is the selection intensity, and $\sigma_{\mathrm{I}}$ is the standard deviation of the index.

Total selection response in monetary units (TSR) is the sum of selection response for all traits in the breeding goal valued by actual goal values for each trait $\left(\mathrm{AGV}_{\mathrm{T}}\right)$ (Groen, 1990):

$$
\mathrm{TSR}=\sum_{\mathrm{i}=1}^{\mathrm{T}} \mathrm{AGV}_{\mathrm{T}} \times \mathrm{SR}_{\mathrm{T}}
$$

Actual goal values are the values corresponding to the real situation at the moment of expression of selection response. Predicted goal values are those used in the breeding goal at the time of selection of the animals, which are included in the equation for selection response $\left(\mathrm{SR}_{\mathrm{T}}\right)$. Correspondingly, the actual breeding goal is the breeding goal containing goal values corresponding to the realized situation at the time of expression of genetic improvement, whereas the predicted breeding goal is the goal on which the selection index and the selection of animals are based. Maximum selection response in monetary units is obtained when predicted circumstances equal actual production circumstances at the moment of expression of genetic improvement. If predicted and actual goal values differ, loss in economic revenue is observed (Groen, 1990). 
The breeding goal $(\mathrm{H})$ was defined according to the approach by Olesen et al. (2000) with the breeding goal being a function of both $\mathrm{NV}$ and $\mathrm{EV}$ for each trait. The breeding goal in this study with 4 traits (MY, MAST, CONCR, and STB) can be written as:

$$
\begin{gathered}
\mathrm{H}=\left(\mathrm{NV}_{\mathrm{MY}}+\mathrm{EV}_{\mathrm{MY}}\right) \times \mathrm{Y}_{\mathrm{MY}}+\left(\mathrm{NV}_{\mathrm{MAST}}+\mathrm{EV}_{\mathrm{MAST}}\right) \times \mathrm{Y}_{\mathrm{MAST}} \\
+\left(\mathrm{NV}_{\mathrm{CONCR}}+\mathrm{EV}_{\mathrm{CONCR}}\right) \times \mathrm{Y}_{\mathrm{CONCR}} \\
+\left(\mathrm{NV}_{\mathrm{STB}}+\mathrm{EV}_{\mathrm{STB}}\right) \times \mathrm{Y}_{\mathrm{STB}}
\end{gathered}
$$

where NV is a nonmarket value for milk yield, mastitis resistance, conception rate, and stillbirth, EV is a market economic value for milk yield, mastitis resistance, conception rate, and stillbirth, $\mathrm{NV}+\mathrm{EV}$ is a goal value, and $\mathrm{Y}$ is a genetic value for milk yield, mastitis resistance, conception rate, and stillbirth, respectively. Each trait in the breeding goal can contain an NV and an EV, as in the example above, but a trait can also contain only an EV (the NV is zero).

Additionally, selection response was divided into nonmarket selection response and market economy selection response:

Nonmarket selection response:

$$
\begin{gathered}
\mathrm{NV}_{\mathrm{MY}} \times \mathrm{SR}_{\mathrm{MY}}+\mathrm{NV}_{\mathrm{MAST}} \times \mathrm{SR}_{\mathrm{MAST}}+\mathrm{NV}_{\mathrm{CONCR}} \times \mathrm{SR}_{\mathrm{CONCR}} \\
+\mathrm{NV}_{\mathrm{STB}} \times \mathrm{SR}_{\mathrm{STB}}
\end{gathered}
$$

Market economy selection response:

$$
\begin{gathered}
\mathrm{EV}_{\mathrm{MY}} \times \mathrm{SR}_{\mathrm{MY}}+\mathrm{EV}_{\mathrm{MAST}} \times \mathrm{SR}_{\mathrm{MAST}}+\mathrm{EV}_{\mathrm{CONCR}} \times \mathrm{SR}_{\mathrm{CONCR}} \\
+\mathrm{EV}_{\mathrm{STB}} \times \mathrm{SR}_{\mathrm{STB}}
\end{gathered}
$$

where further SR is nonmarket selection response or market selection response for milk yield, mastitis, conception rate, and stillbirth.

\section{Derivation of NV Using Selection Index Theory}

We applied 2 methods based on selection index theory to derive NV. The first method was restricted indices. Desired gain indices have been suggested as a tool to derive NV. In addition, a combination of desired gain indices and EV might reduce undesirable effects such as negative response in traits from using a selection index purely based on EV (Brascamp, 1984; Christensen, 1998a). A restricted index is a special case of a desired gain index because the desired genetic change in one or more traits is zero (Brascamp, 1984). The outcome from a restricted index is the goal value $(\mathrm{NV}$ $+\mathrm{EV})$ required to obtain zero genetic change in a given trait. The NV can then be derived as the difference between the goal value required to obtain zero change in a given trait and the EV (Olesen et al., 1999). Theory by Kempthorne and Nordskog (1959) and Tallis (1962) was applied for the restricted indices. For computational reasons, we used an iterative approach with different levels of $\mathrm{NV}$ to solve for the value that yielded zero genetic change in each of the traits of interest. Using restricted indices, NV for MAST and CONCR were derived both by individually and simultaneously restricting genetic change to zero for the traits. We here assumed the predicted breeding goal to include only $\mathrm{EV}$, whereas the actual breeding goal included both EV and NV. This allowed us to quantify selection response in a situation where NV are excluded from the breeding goal, even if they exist and to partition part of the selection response to nonmarket factors.

The second method to derive NV was based on the loss in selection response for milk yield by adding an $\mathrm{NV}$ to functional traits in a breeding goal including EV only. By quantifying the milk vs. functional traits tradeoff, users are allowed to consider the trade-off from the perspective of their own situation. Selection response for MY was predicted by adding different levels of NV to the EV (Table 1) for the functional traits (MAST, CONCR, and STB). Percentage loss in selection response for milk yield was then calculated as predicted selection response for milk yield for a breeding goal containing both $\mathrm{EV}$ and $\mathrm{NV}$ relative to selection response for milk yield for a breeding goal containing EV only (note that in contrast to the method described above, the predicted breeding goal here includes both $\mathrm{NV}$ and EV, whereas the actual breeding goal includes only EV). Response for each functional trait was then quantified for the different levels of loss in selection response for milk yield and corresponding goal values $(\mathrm{NV}+\mathrm{EV})$ were derived. Finally, the NV was derived as the difference between the goal value and the EV.

However, before deriving NV using the 2 methods described above, we quantified the effect on selection response by adding different levels of NV for MAST and CONCR to a breeding goal including only NV. As when deriving NV based on the loss in selection response as described in the previous paragraph, the actual breeding goal included EV only (Table 1), which represents the currently applied Danish breeding goal. The predicted breeding goal included $\mathrm{EV}$ and, in addition, different levels of NV for either MAST or CONCR. By including NV in the predicted breeding goal but valuing selection response according to the actual breeding goal ( $\mathrm{EV}$ only), we quantified the loss in total current market economic selection response by including NV for functional traits in the breeding goal.

\section{RESULTS}

\section{Effects on Selection Response by Including NV in the Breeding Goal}

Selection response for MAST was $-7.4 € /$ cow per year for a breeding goal containing EV only (Table $2 ; 1 €=$ 
Table 2. Total selection response and selection response for milk yield, mastitis resistance, conception rate, and stillbirth at 11 nonmarket values (NV) for mastitis resistance. The actual breeding goal includes only market economic values for milk yield, mastitis resistance, conception rate, and stillbirth. The predicted breeding goal includes market economic values for all 4 traits plus different nonmarket values for mastitis resistance.

\begin{tabular}{rlllllllll}
\hline & \multicolumn{7}{c}{ Selection response (€/cow per yr) } \\
\cline { 2 - 10 } $\begin{array}{l}\text { NV }^{1} \\
(€ / \text { Incidence) }\end{array}$ & $\mathrm{r}_{\text {IA* }^{*}}{ }^{2}$ & $\mathrm{r}_{\mathrm{IA}}{ }^{3}$ & Milk & Mastitis & $\begin{array}{l}\text { Conception } \\
\text { rate }\end{array}$ & Stillbirth & Total & $\begin{array}{l}\mathrm{NV}^{4} \\
(\%)\end{array}$ & $\begin{array}{l}\text { Loss }^{5} \\
(\%)\end{array}$ \\
\hline 0 & 0.88 & 0.88 & 141.0 & -7.4 & -5.1 & 1.0 & 129.5 & 0.0 & 0.00 \\
10 & 0.87 & 0.88 & 139.7 & -6.3 & -5.0 & 1.0 & 129.5 & 6.1 & 0.03 \\
20 & 0.87 & 0.88 & 138.4 & -5.1 & -4.9 & 1.0 & 129.4 & 12.3 & 0.1 \\
30 & 0.86 & 0.88 & 136.9 & -3.9 & -4.7 & 1.0 & 129.2 & 18.4 & 0.2 \\
40 & 0.85 & 0.87 & 135.4 & -2.8 & -4.6 & 1.0 & 129.0 & 24.5 & 0.4 \\
50 & 0.85 & 0.87 & 133.8 & -1.7 & -4.5 & 1.0 & 128.6 & 30.7 & 0.7 \\
60 & 0.84 & 0.87 & 132.1 & -0.5 & -4.4 & 1.0 & 128.3 & 36.8 & 1.0 \\
70 & 0.83 & 0.87 & 130.4 & 0.6 & -4.3 & 1.0 & 127.8 & 42.9 & 1.3 \\
80 & 0.83 & 0.86 & 128.6 & 1.8 & -4.1 & 1.0 & 127.3 & 49.1 & 1.7 \\
90 & 0.82 & 0.86 & 126.7 & 2.9 & -4.0 & 1.0 & 126.6 & 55.2 & 2.2 \\
100 & 0.82 & 0.85 & 124.8 & 4.1 & -3.9 & 1.0 & 126.0 & 61.3 & 2.7 \\
\hline
\end{tabular}

${ }^{1} 1 €=\$ 1.20$ (August 31, 2004).

${ }^{2}$ Correlation between index and predicted breeding goal.

${ }^{3}$ Correlation between index and actual breeding goal.

${ }^{4}$ Nonmarket value/market economic value $\times 100$, market economic value $=€ 163 /$ incidence.

${ }^{5}$ Loss in total selection response by including a nonmarket value for mastitis compared to total selection response using the actual breeding goal where nonmarket value for mastitis is zero.

\$1.20). Adding an NV for MAST increased selection response not only for MAST but also for CONCR. However, selection response for MY decreased with increasing levels of NV for MAST. Only minor losses in total selection response were observed by adding an NV for MAST. For example, the loss in total selection response to obtain zero response in MAST was around 1.1\%. This loss was the difference between total selection response in the situation with only $\mathrm{EV}$ ( $\mathrm{NV}=0$ is the actual breeding goal) and selection response in the situation with both $\mathrm{EV}$ and $\mathrm{NV}$ for mastitis (predicted breeding goal). There was a higher reduction in the correlation between the index and the predicted breeding goal with increasing NV compared with the correlation between the index and the actual breeding goal.

When an NV for CONCR was included (Table 3), reduced selection response for MY, and more positive trends for CONCR and MAST were observed. Compared with MAST, a higher relative NV was needed to obtain positive selection response for CONCR. In addition, the observed total selection response was lower to attain positive selection response for CONCR than for MAST.

\section{Derivation of NV}

Nonmarket selection response, market selection response, and derived NV based on restricted indices are presented in Table 4 for 4 predicted breeding goals. The predicted breeding goal 1 includes only EV. In breeding goals 2 and 3, NV for MAST and CONCR were indepen- dently derived based on restricted indices. The predicted breeding goals then include EV for all traits and derived NV for either MAST or CONCR. The predicted breeding goal 4 includes both EV and simultaneously derived NV for both MAST and CONCR. For all 4 breeding goals, the actual breeding goal was assumed to be the breeding goal in alternative 4 (EV for all 4 traits and NV for both MAST and CONCR). This means that selection response for each of the 4 traits is valued according to the goal values in breeding goal 4 .

Using restricted indices, independently derived NV for MAST and CONCR were $64.5 € /$ incidence and 5.2 $€ / \%$ (breeding goals 2 and 3 ). When derived simultaneously, NV were $19.6 € /$ incidence for MAST and $4.9 € /$ $\%$ for CONCR.

The predicted breeding goal 1 includes only EV. However, because selection response is valued according to actual breeding goal (4), which includes NV for CONCR and MAST, some of the selection response is partitioned to nonmarket factors. For example, the nonmarket response for CONCR of $-12.7 € /$ cow per year is from the response of -2.58 in CONCR valued by the $\mathrm{NV}$ of CONCR from breeding goal 4 of $4.94 €$.

The total nonmarket response in breeding goal 1 of $-13.6 € /$ cow per year was mainly due to the high negative nonmarket response for conception rate $(-12.7 € /$ cow per year). The $-13.6 € /$ cow per year is the loss in response by excluding NV from the breeding goal, if they existed. This means that the predicted breeding goal includes EV only, but the actual breeding goal 
Table 3. Total selection response and selection response for milk yield, mastitis resistance, conception rate, and stillbirth at 13 nonmarket values (NV) for conception rate. The actual breeding goal includes only market economic values. The predicted breeding goal includes market economic values for all 4 traits plus different nonmarket values for conception rate.

\begin{tabular}{|c|c|c|c|c|c|c|c|c|c|}
\hline \multirow[b]{2}{*}{$\begin{array}{l}\text { NV } \\
(€ / \%)\end{array}$} & \multicolumn{9}{|c|}{ Selection response ( $€ /$ cow per yr) } \\
\hline & $\mathrm{r}_{\mathrm{IA}^{*}}{ }^{1}$ & $\mathrm{r}_{\mathrm{IA}}^{2}$ & Milk & Mastitis & $\begin{array}{l}\text { Conception } \\
\text { rate }\end{array}$ & Stillbirth & Total & $\begin{array}{l}\mathrm{NV}^{3} \\
(\%)\end{array}$ & $\begin{array}{l}\operatorname{Loss}^{4} \\
(\%)\end{array}$ \\
\hline 0 & 0.88 & 0.88 & 141.0 & -7.4 & -5.1 & 1.0 & 129.5 & 0.0 & 0.0 \\
\hline 0.5 & 0.87 & 0.88 & 140.0 & -6.9 & -4.6 & 1.0 & 129.4 & 25.3 & 0.1 \\
\hline 1 & 0.87 & 0.88 & 138.9 & -6.4 & -4.2 & 1.0 & 129.3 & 50.5 & 0.2 \\
\hline 1.5 & 0.86 & 0.87 & 137.6 & -6.0 & -3.7 & 1.0 & 129.0 & 75.8 & 0.5 \\
\hline 2 & 0.85 & 0.87 & 136.2 & -5.5 & -3.2 & 1.0 & 128.6 & 101.0 & 1.0 \\
\hline 2.5 & 0.86 & 0.87 & 134.7 & -5.0 & -2.7 & 1.0 & 128.0 & 126.3 & 1.5 \\
\hline 3 & 0.86 & 0.87 & 132.9 & -4.4 & -2.2 & 1.0 & 127.3 & 151.5 & 2.2 \\
\hline 3.5 & 0.85 & 0.87 & 131.1 & -3.9 & -1.7 & 1.0 & 126.5 & 176.8 & 3.0 \\
\hline 4 & 0.85 & 0.87 & 129.1 & -3.4 & -1.2 & 1.0 & 125.5 & 200.2 & 4.0 \\
\hline 4.5 & 0.85 & 0.86 & 126.9 & -2.8 & -0.7 & 1.0 & 124.4 & 227.3 & 5.1 \\
\hline 5 & 0.84 & 0.86 & 124.6 & -2.3 & -0.2 & 1.1 & 123.1 & 252.5 & 6.4 \\
\hline 5.5 & 0.84 & 0.86 & 122.1 & -1.7 & 0.3 & 1.1 & 121.8 & 277.8 & 7.8 \\
\hline 6 & 0.83 & 0.85 & 119.6 & -1.2 & 0.8 & 1.1 & 120.3 & 303.0 & 9.3 \\
\hline
\end{tabular}

${ }^{1}$ Correlation between index and predicted breeding goal.

${ }^{2}$ Correlation between index and actual breeding goal.

${ }^{3}$ Nonmarket value/market economic value $\times 100$; market economic value $=€ 1.98 / \%$.

${ }^{4}$ Loss in total selection response by including a nonmarket value for conception rate compared with total selection response using the actual breeding goal where nonmarket value for conception rate is zero.

includes an NV for mastitis. Nonmarket response for MAST in breeding goal 1 was low (-0.9) compared with the market response $(-7.4)$. Total selection response (market + nonmarket) differed only slightly between the 4 breeding goals. Total market selection response was $129.5 € /$ cow per year for breeding goal 1 but de- creased to $122.5 € /$ cow per year for breeding goal 4 . This loss $(7 \%)$ can reflect a loss in short-term response because of long-term NV. The loss was mainly due to decreased response for milk (from 141 to $121.4 € /$ cow per year). The loss in market selection response by adding an NV for MAST (breeding goal 4) to a breeding

Table 4. Derived nonmarket values (NV), market economic values (EV), total goal values (EV + NV) and selection response (market, nonmarket, and total) for 4 predicted breeding goals. Breeding goal 1 includes only EV for milk yield, mastitis resistance, conception rate, and stillbirth. Market economic values for all 4 traits plus an NV for mastitis resistance are included in breeding goal 2 . Breeding goal 3 includes EV for all traits and an NV for conception rate. Breeding goal 4 includes EV for all 4 traits and NV for mastitis and conception rate. For all 4 predicted breeding goals, breeding goal 4 is assumed to be the actual breeding goal.

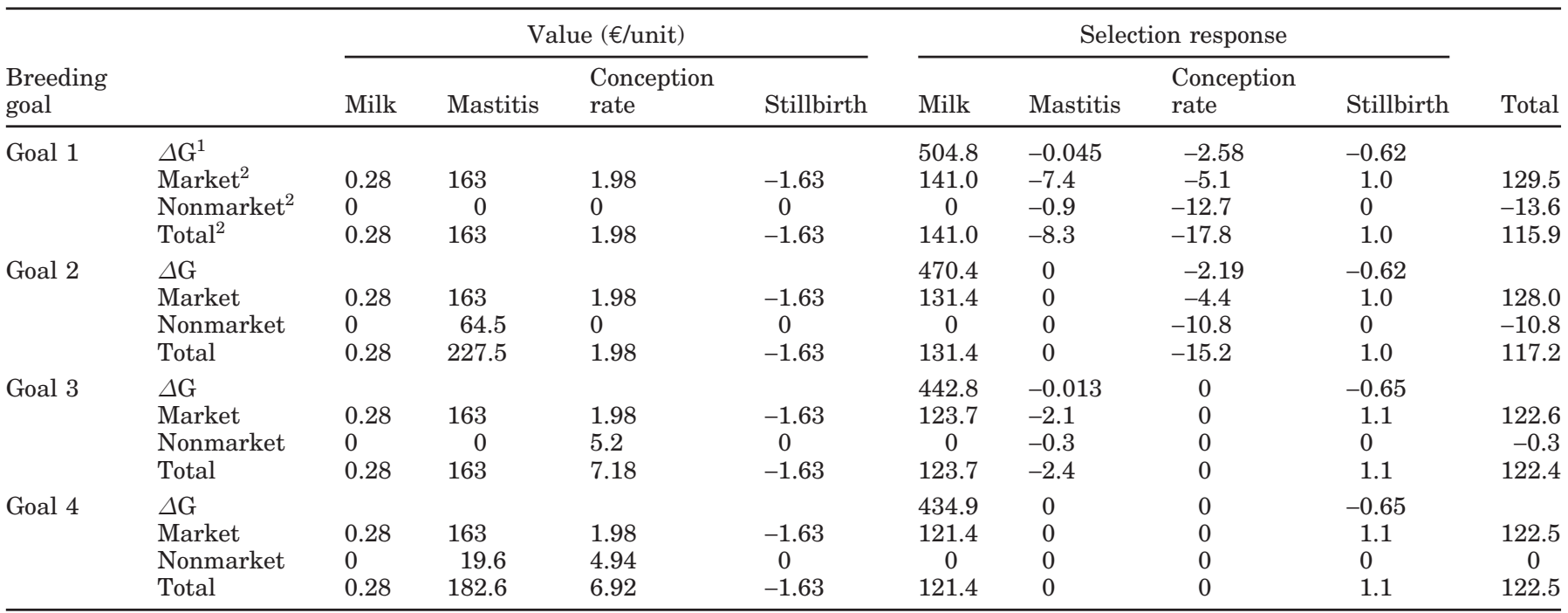

\footnotetext{
${ }^{1}$ Selection response in absolute units, milk $=\mathrm{kg} ;$ mastitis resistance $=$ incidence conception rate $=\% ;$ stillbirth $=\%$.

${ }^{2}$ Selection response of selected bulls in $€ /$ cow per yr.
} 


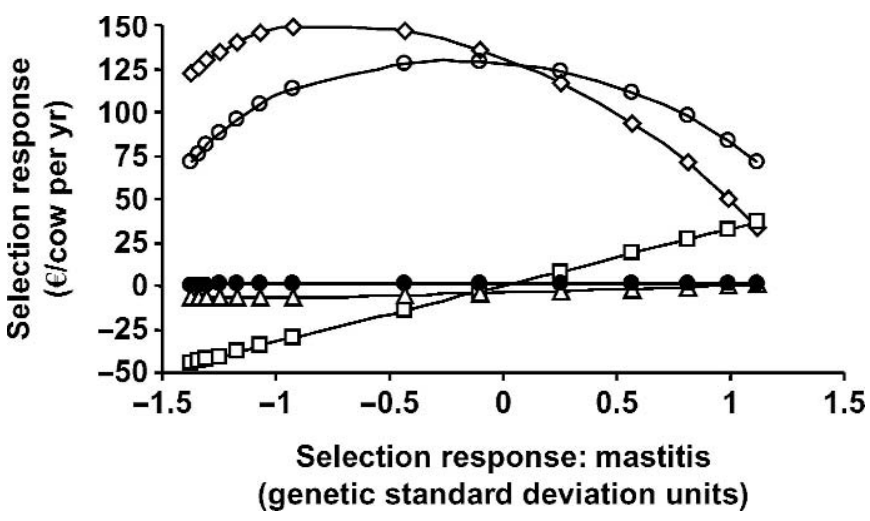

Figure 1. Selection response (€/cow per yr) for milk yield $(\diamond)$, stillbirth $(\bullet)$, conception rate $(\Delta)$, mastitis resistance $(\square)$, and total $(\bigcirc)$ as a function of selection response of mastitis resistance in genetic standard deviation units. The $\mathrm{x}$-axis (with different levels of selection response of mastitis) was calculated by varying the goal value for mastitis resistance. The actual breeding goal includes only market economic values, whereas the predicted breeding goal includes both market economic values and varying levels of nonmarket values for mastitis resistance.

goal containing an NV for CONCR (breeding goal 3) was negligible.

The second method was based on how much of the response in MY farmers or breeding companies may be willing to forego to achieve a given genetic improvement for functional traits. Figure 1 shows that total response and response in other traits change by increasing positive response for MAST. Figure 1 is a result of a simulation with varying levels of NV for MAST. The actual breeding goal includes only EV, whereas the predicted breeding goal includes both EV and varying levels of NV for MAST. Total selection response was highest with selection response for MAST of -0.23 genetic standard deviation units. Increased response for MAST had a slightly positive influence on selection response for CONCR, whereas STB remained constant. However, increased selection response for MAST had a negative effect on response for MY, especially when selection response for MAST became positive.

Figure 2 shows how increased selection response for the functional traits is at the expense of MY. Selection response for MY in absolute units $(\mathrm{kg})$ is given as a function of selection response for MAST, CONCR, and STB, respectively. As with the previous figure, this figure is a result of simulation with varying levels of $\mathrm{NV}$ for the functional traits. The 3 graphs in Figure 2 can be divided into 3 regions. The first region of the graphs represents a situation with low selection response for MY due to suboptimal goal values on MAST, CONCR, and STB. The second part of the graph is the optimum selection response for MY $(504.8 \mathrm{~kg})$ with EV. Selection responses for MAST, CONCR, and STB at this point

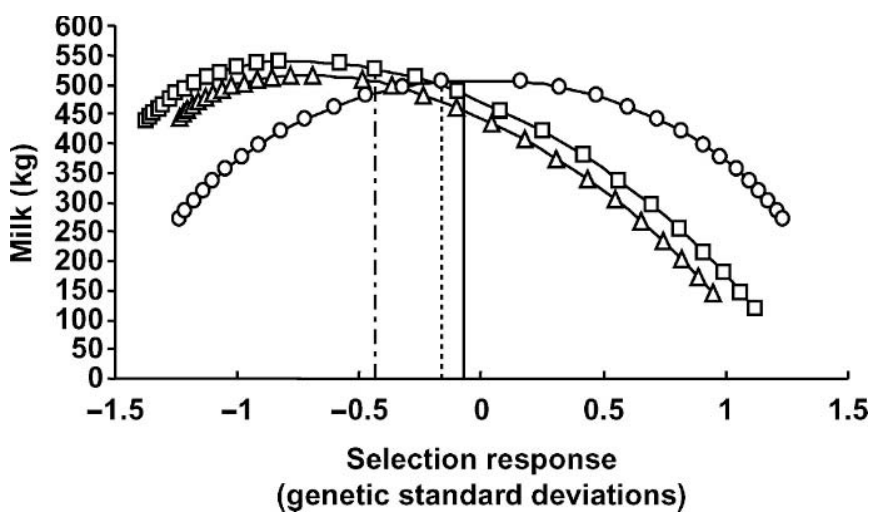

Figure 2. Selection response for milk yield (kg) as a function of genetic superiorities for mastitis resistance $(\square)$, conception rate $(\Delta)$, or stillbirth $(\bigcirc)$ given in genetic standard deviation units. Selection response for mastitis resistance $(\cdots \cdots)$, conception rate $(-\cdot-\cdot)$, and stillbirth $(-)$ with only market economic values in the breeding goal. Selection response for milk yield for a breeding goal with market economic values only is $504.8 \mathrm{~kg}$.

are $-0.23,-0.45$, and -0.12 , respectively. In the third region of the graph, selection response for $\mathrm{MY}$ is lower than at the point with EV only $(504.8 \mathrm{~kg})$ due to increased selection emphasis on the functional traits caused by higher goal values on the traits. For example, by increasing the goal value to attain zero selection response for CONCR, selection response for MY is 443 $\mathrm{kg}$, corresponding to a loss in response for MY of $61.8 \mathrm{~kg}$.

Figure 3 demonstrates how results from Figure 2 can be used to derive NV based on how much selection response in MY that one is willing to forego to improve

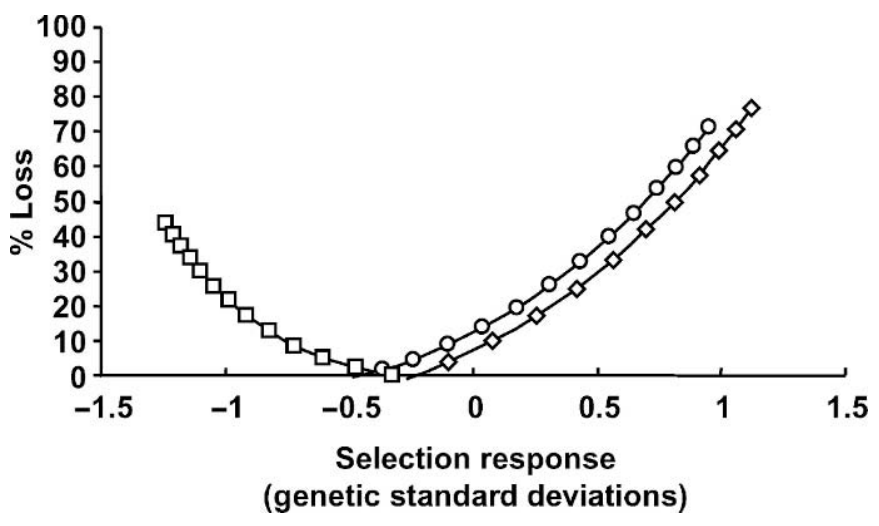

Figure 3. Percentage loss in selection response for milk yield by including a nonmarket value for the functional traits in the breeding goal compared to a situation with economic values only as a function of selection response for mastitis resistance $(\diamond)$, conception rate $(\bigcirc)$, and stillbirth $(\square)$ in genetic standard deviation units. In the situation with economic values only, genetic superiorities for mastitis resistance, conception rate, and stillbirth are $-0.23,-0.45$, and -0.12 genetic standard deviation units and selection response for milk is $504.8 \mathrm{~kg}$. 
the functional traits. Selection response for MY in absolute units from Figure 2 is expressed as percentage loss in selection response for milk by including an NV for the functional traits in the breeding goal compared with the situation with only EV (selection response = $504.8 \mathrm{~kg})$.

With 5, 10, and 15\% loss in selection response for MY, selection response for MAST are $-0.05,0.09$, and 0.21 genetic standard deviations (Figure 3). Corresponding $\mathrm{NV}$ are 49,89 , and $124 € /$ incidence. With 5, 10 , and $15 \%$ loss in selection response for milk, NV for CONCR are 2.7, 4.5, and 5.9 €/\%, respectively. Corresponding values for STB are $-4.7,-7.5$, and $-9.9 € / \%$ (note that the favorable direction of selection is toward negative selection response for STB). The curves for MAST and CONCR follow each other closely. However, the curve for STB seems to differ. By accepting a 5\% loss in selection response for MY, selection response for STB increases by 0.35 genetic standard deviations, whereas selection response for MAST increases by only 0.18 genetic standard deviations.

\section{DISCUSSION}

\section{Effects on Selection Response of Including $\mathrm{NV}$ in the Breeding Goal}

Nonmarket values for MAST and CONCR derived separately using restricted indices were 0.4 and 2.6 times the value of the EV, respectively. Nonmarket values for MAST and CONCR were both lower when derived simultaneously than when derived individually. When derived simultaneously, the NV for MAST was only one-third of the value when derived individually. This is because the 2 traits are positively correlated and both of them are negatively correlated with MY.

Loss in total selection response was about $1 \%$ by keeping MAST constant, whereas the loss was about $7 \%$ by keeping CONCR constant, when valued according to actual EV. With simultaneous derivation of $\mathrm{NV}$ for both MAST and CONCR, the loss in total response was only slightly higher than in the situation with $\mathrm{NV}$ for CONCR only. This indicates that there are no further losses when adding an NV for MAST compared to a situation with NV for CONCR only. For both CONCR and MAST, most of the loss in total selection response was due to decreased selection response for MY. Including an NV for MAST in the breeding goal increased selection response for CONCR and vice versa. This was due to relatively more selection emphasis on the functional traits compared with MY, and because MAST and CONCR are positively correlated and both of them are negatively correlated with MY.
Olesen et al. (2000) found reductions in selection response of about $10 \%$ if $\mathrm{NV}$ existed, but were ignored. They predicted selection response using an index with 4 traits (milk, mastitis, beef, and fertility) and 3 breeding goals (note the error in figures for selection response in alternative 1, which should have been: $315.6,-40.2$, and 275.4 Norwegian Kroner for market economy response, nonmarket response, and total response). Results by Olesen et al. (2000) correspond well with results obtained in this study (Table 4). One problem is how to value selection response, that is, which breeding goal is considered the actual breeding goal at the time of expression of genetic improvement. In the first part of this study, we quantified total selection response and loss in total response by including NV in the breeding goal assuming the actual breeding goal to include EV only. This breeding goal reflects a shortsighted breeding goal, with a high EV for MY. The EV represent what we expect in the short term. In contrast, NV represent a longsighted view aimed at improving functional traits beyond what we know is economically profitable today by taking into account other aspects (e.g., ethical), which is not reflected in market prices or costs. However, future production circumstances are uncertain. Losses in revenues of the breeding program occur if actual production circumstances at the time of expression of genetic improvement differ from the predicted circumstances (when selection decisions were made) (Groen, 1990). The loss in total selection response by excluding NV for MAST and CONCR can be considered as a risk of improving milk production at the expense of animal health and welfare. Risk is an important factor when discussing a definition for sustainable breeding. Keeping different stocks can minimize the risk represented by uncertain future production circumstances as discussed by Smith (1985).

\section{Methods to Derive NV}

With zero genetic changes in MAST and CONCR as in the restricted indices, it is assumed that the current levels of MAST and CONCR are socially and culturally acceptable. This may not be the case. However, it is difficult to obtain an objective level for the desired change in a given trait. In the second method, the NV of a trait was derived based on an acceptable level of loss in selection response for MY. The main part of the total response was due to response in MY, and increasing response for the functional traits resulted in loss in total selection response. Therefore, high selection response for MY is advantageous. With the desired gain or restricted index approach, it is possible to specify a desired change in several traits simultaneously. With simultaneous derivation of NV for multiple traits, 
it has to be decided how the reduction in selection response for milk should be distributed to the benefit in response for each of the functional traits.

There is some dispute in the literature regarding the efficiency of using desired gain versus economic indices. Gibson and Kennedy (1990) found that constrained indices caused severe losses in genetic gain and stated that these should not be used when the goal was to improve economic merit. Yamada (1995) however, found a desired gain index to be more efficient than an economic index when the profit function was nonlinear. Brascamp (1984) and Christensen (1998a) suggested combining selection indices based on market economic values and selection indices with constraints. This could reduce undesirable effects, such as negative response in some traits obtained using a selection index based on market economic values. This was supported in the current study.

The derivation of $\mathrm{NV}$ by restricted indices or desired gain indices is based solely on a desired change in a certain trait and not on profit of the farmer. Profit maximization corresponds to the perspective of the farmer, which usually has been chosen as the interest of selection when deriving market economic values (Groen et al., 1997). However, the interest of selection of the farmer does not necessarily correspond to the interest of consumers or the society as a whole (Olesen et al., 2000). Breeding goals based on a long-term perspective requires additional policies, and other decision makers need to be involved (Olesen et al., 2000). Therefore, it is not sufficient to derive goal values at farm level. Higher levels of the production system must be considered, which was done in this study by mimicking the agricultural sector using index selection.

Olesen et al. (1999, 2000) characterized possible future agricultural systems and potential animal breeding strategies. The potential breeding strategies in many cases referred to a broader definition of breeding goals, which balanced gain in productivity with improvements in functional traits. High productivity is undoubtedly still needed in the future. This justifies the method to derive nonmarket values based on accepted loss in selection response for milk. However, the choice of acceptable loss in response for milk is subjective. It may appeal directly to farmers because it gives a value to response for a functional trait relative to loss in milk yield, which is the farmers' main income. In addition, it directly shows to the public, the loss farmers are willing to take to improve the functional traits. In the future, cultural and social aspects such as concerns of animal welfare may become increasingly important. As defined by Olesen et al. (2000), it is reductionist thinking to presume that farmers or breeding companies will accept all of the costs associated with ethical and societal considerations for food-producing animals. Because it is in the interests of society to have ethically produced and societally acceptable food, whether society should share the extra costs associated with sustainable animal production warrants further discussion.

There are several other methods available to derive nonmarket values (Olesen et al., 1999), which are mainly based on consumer preferences. Literature regarding the application of those methods for the derivation of nonmarket values is scarce. von Rohr et al. (1999) applied the contingent valuation method to derive goal values for meat quality traits in pigs. Nonmarket values were derived based on answers from interviews where meat quality experts from slaughter and retail companies were asked how much they were willing to pay for a certain product.

A nonmarket value can be an ethical value of improved animal welfare through less suffering from diseases or stress and a higher quality of life or values of natural capital and ecosystem services (Olesen et al., 2000). Hence, a nonmarket value also covers the value of genetic improvement, which is not reflected in the current market. The term "nonmarket" may seem confusing as it seems that the market influences most values in the long run, e.g., recently through eco-labeled food. However, this presupposes that consumers are informed about the consequences of different breeding goals. A study by Quédrago (2003) showed that consumers have poor knowledge about breeding and reproduction procedures. Hence, many consumers are not willing to pay more for products indicating improved welfare of the cow, and some may not buy these products. In such cases, the ethical value of improved animal welfare would not be fully expressed in the market. However, there may be a political will to improve animal welfare through legislation, for example, on the incidence of mastitis allowed or through subsidies (incentives) or taxes.

\section{CONCLUSION}

The main objective of this study was to present methods to derive nonmarket values for functional traits in dairy cattle. Nonmarket values for mastitis resistance, conception rate, and stillbirth were derived using restricted indices and by determining levels of loss in milk yield response that farmers or breeding companies may be willing to forego by improving functional traits. Relative to market economic values, nonmarket values differed between the 3 traits due to differences in market economic values and genetic parameters. It was shown that it is possible to assign nonmarket values to functional traits in dairy cattle breeding goals. The 
approach in the Scandinavian countries with broadly defined breeding goals is a step toward a more sustainable breeding goal. However, in this study we showed that further genetic improvement for functional traits in dairy cattle breeding programs is possible by including nonmarket values in the breeding goal with only minor losses in total selection response.

\section{ACKNOWLEDGMENTS}

Ingrid Olesen is gratefully acknowledged for useful comments regarding the manuscript.

\section{REFERENCES}

Brascamp, E. W. 1984. Selection indices with constraints. Anim. Breed. Abstr. 52:645-654.

Brascamp, E. W., C. Smith, and D. R. Guy. 1985. Derivation of economic weights from profit equations. Anim. Prod. 40:175-180.

Christensen, L. G. 1998a. Future market and consumer-oriented breeding goals. Acta Agric. Scand. A Anim. Sci. 28:45-53.

Christensen, L. G. 1998b. Possibilities for genetic improvement of disease resistance, functional traits and animal welfare. Acta Agric. Scand. A Anim. Sci. 29(Suppl. 28):77-89.

Dekkers, J. C. M., and J. P. Gibson. 1998. Applying breeding objectives to dairy cattle improvements. J. Dairy Sci. 81(Suppl. 2):19-35.

Gibson, J. P., and B. W. Kennedy. 1990. The use of constrained selection indexes in breeding for economic merit. Theor. Appl. Genet. 80:801-805.

Groen, A. F. 1989. Cattle breeding goals and production circumstances. Ph.D. Thesis, Wageningen Agricultural University, the Netherlands.

Groen, A. F. 1990. Influences of production circumstances on the economic revenue of cattle breeding programmes. Anim. Prod. 51:469-480.

Groen, A. F., T. Steine, J.-J. Colleau, J. Pedersen, J. Pribyl, and N. Reinsch. 1997. Economic values in dairy cattle breeding, with special reference to functional traits. Report of an EAAP working group. Livest. Prod. Sci. 49:1-21.

Kempthorne, O., and A. W. Nordskog. 1959. Restricted selection indices. Biometrics 5:10-19.

Mark, T. 2004. Applied genetic evaluations for production and functional traits in dairy cattle. J. Dairy Sci. 87:2641-2652.

Nielsen, H. M. 2004. Economic values for production and functional traits in dairy cattle breeding goals derived by stochastic simulation. Ph.D. Thesis, Royal Veterinary and Agricultural University, Copenhagen, Denmark.

Olesen, I., B. Gjerde, and A. F. Groen. 1999. Methodology for deriving nonmarket trait values in animal breeding goals for sustainable production systems. Proc. Int. Workshop on EU Concerted Action on Genetic Improvement of Functional Traits in Cattle (GIFT). Wageningen, the Netherlands. Interbull Bull. 23:13-21.

Olesen, I., A. F. Groen, and B. Gjerde. 2000. Definition of animal breeding goals for sustainable production systems. J. Anim. Sci. 78:570-582.

Quédrago, A. P. 2003. Symbolic goods in the market place. Public perceptions of farm animal breeding and reproduction in France and United Kingdom. Pages 36-46 in SEFABAR (Sustainable European Farm Animal Breeding and Reproduction), A. E. Liinamo and A. M. Neeteson-van Niewenhoven, ed. Final Workshop, Rome, Italy.

Rauw, W. M., E. Kanis, E. N. Noordhuizen, and F. J. Grommers. 1998. Undesirable side effects of selection for high production efficiency in farm animals: A review. Livest. Prod. Sci. 56:13-33.

Sandøe, P., B. L. Nielsen, L. G. Christensen, and P. Sørensen. 1999. Staying good while playing God-The ethics of breeding farm animals. Anim. Welf. 8:313-328.

Smith, C. 1985. Scope for selecting many breeding stocks of possible economic value in the future. Anim. Prod. 41:403-412.

Sørensen, M. K. 1999. Stochastic simulation of breeding schemes for dairy cattle. Report, Danish Institute of Agricultural Sciences, Foulum, Denmark. (In Danish with English summary).

Tallis, G. M. 1962. A selection index for optimum genotype. Biometrics 18:120-122.

Torp Donner, H., and J. Juga. 1997. Sustainability-A challenge to animal breeding. Agric. Food Sci. Finl. 6:229-239.

von Rohr, P., A. Hofer, and N. Künzi. 1999. Economic values for meat quality traits in pigs. J. Anim. Sci. 77:2633-2640.

Yamada, Y. 1995. Are economic selection indices always superior to a desired gains index? Theor. Appl. Genet. 91:655-658. 